\title{
Molecular Diagnosis of Atlantic Forest Mammals Using Mitochondrial DNA Sequences: Didelphid Marsupials
}

\author{
Juliander Agrizzi ${ }^{1}$, Ana Carolina Loss ${ }^{1}$, Ana Paula C. Farro ${ }^{2}$, Rafaela Duda ${ }^{1}$, Leonora P. Costa $^{1}$ and \\ Yuri L. R. Leite*,1 \\ ${ }^{1}$ Departamento de Ciências Biológicas, Centro de Ciências Humanas e Naturais, Universidade Federal do Espírito \\ Santo, Av. Marechal Campos 1468, Maruípe, 29043-900 Vitória, ES, Brazil \\ ${ }^{2}$ Departamento de Ciências Biológicas e Agrárias, Centro Universitário Norte do Espírito Santo, Universidade Federal \\ do Espírito Santo, Rodovia BR-101 Norte Km 60, Bairro Litorâneo, 29932-540 São Mateus, ES, Brazil
}

\begin{abstract}
Most living species of New World marsupials are classified in the family Didelphidae, with 98 species and 18 genera currently recognized. We sequenced fragments of two mitochondrial genes of didelphid marsupials from the Atlantic Forest of eastern South America, a biodiversity hotspot. We evaluated sequence divergences within and among species and contrasted the efficiency of cytochrome c oxidase subunit I (COI) with cytochrome b (CytB) in species-level diagnosis. The average intraspecific genetic divergence of $\mathrm{COI}$ and $\mathrm{CytB}$ was $2.0 \%$ and $1.9 \%$, respectively; which was about five times lower than the comparison among species of the same genus (11.2 and 10.8\%). In both genes, divergence levels among closely related species are usually higher than within species. The barcoding gap is similar in COI and CytB, indicating that either gene can be used in molecular diagnoses of didelphid species. DNA barcodes are a welcome addition to traditional taxonomic methods when viewed as additional diagnostic characters in the context of integrative taxonomy.
\end{abstract}

Keywords: Cytochrome b, Cytochrome oxidase I, DNA barcodes, Integrative taxonomy, Mammals.

\section{INTRODUCTION}

Most living species of New World marsupials are classified in the family Didelphidae, which has a geographic range from southeastern Canada to southern Argentina. They are important components of the Neotropical mammalian fauna, usually comprising the third most diverse group (after bats and rodents) at a given rainforest locality [1]. There were 91 species and 18 genera of didelphid marsupials recognized in a recent taxonomic compilation [2]. In the face of such diversity, the paucity of studies on systematic limits and appropriate species diagnosis is remarkable [3]. Nevertheless, didelphid taxonomy has been very dynamic in recent decades. The number of recognized species increased $36 \%$ from 69 to 94 in 12 years when we compare subsequent editions of the most influential taxonomic reference to living mammals of the world $[4,5]$. This increase is mainly due to the description of new species, or the split of widespread taxa formerly lumped into one polytypic species. Recent systematic revisions have even resulted in the description of new didelphid genera, such as Chacodelphys and Cryptonanus [6, 7]. In addition, several classification schemes above the species level have been proposed throughout the years, but robust phylogenetic analyses based on abundant molecular and morphological data and dense taxon sampling has only just become available [8].

\footnotetext{
*Address correspondence to this author at the Departamento de Ciências Biológicas, Universidade Federal do Espírito Santo, Av. Marechal Campos 1468, Maruípe, 29043-900 Vitória, ES, Brazil; Tel: +55-27-3335-7495; Fax: +55-27-3335-7250; E-mail: yleite@gmail.com
}

Knowledge about species diversity, as well as the evolutionary relationships among species can only be acquired with appropriate taxonomic identification at the species level. Traditional morphological analyses have been used extensively for centuries as a successful tool for diagnosing species [9]. However, many species have phenotypic plasticity, sexual dimorphism or ontogenetic changes in morphological characters, hindering species identification [10]. Cryptic species are common in many groups and their identification has always been a challenge, but the advent of relatively inexpensive and rapid DNA sequencing has given biologists a new tool for detecting and differentiating morphologically similar species [11]. In these cases, reliable species identification can be achieved with the analysis of a short segment from the genome, or a specific DNA barcode [12]. DNA barcodes offer additional diagnostic characters, and may be exceptionally helpful in species identification, especially when integrated with traditional morphological approaches [13].

The cytochrome c oxidase subunit I (COI) mitochondrial region has emerged as the standard barcode region for animals, including mammals (www.mammaliabol.org). The selection of this gene fragment is based on general characteristics of mitochondrial DNA, the standard choice of genome to use in phylogeographic studies. These features include rapid accumulation of mutations, lack of introns, high number of copies per cell, negligible recombination rate, and haploid inheritance [14]. Most importantly, the efficiency of DNA barcodes depends on the existence of a large barcoding "gap" between intra- and interspecific variation [15]. Interspecific divergences in COI sequences are significantly 
higher than intraspecific variation in many groups of animals $[16,17]$, but there are exceptions $[18,19]$. COI sequences have been used in diagnosing species in many animal groups, including mammals $[20,21]$. Only a few didelphid species have been characterized using standardized barcoding protocols in one study [21], based on 32 specimens from northern South America (mainly from Surinam and Guyana) and a few scattered points in Central America. In the present paper, we expand the COI sequence database of didelphid marsupials to species from the Atlantic Forest of eastern South America, one of the top biodiversity hotspots in the world [22]. Our main goals were to evaluate sequence divergences within and among didelphid species and to compare the efficiency of COI in species diagnosis with the mitochondrial cytochrome b gene (CytB), the traditional marker in species level taxonomy of mammalian species [23].

\section{MATERIAL AND METHODS}

DNA was extracted from tissue samples (muscle or liver) fixed in ethanol and housed at Universidade Federal do Espírito Santo (UFES), Vitória, Brazil and Museu de Biologia Professor Mello Leitão (MBML), Santa Teresa, Brazil. We followed the taxonomy of Gardner [2], and not the most recent revision by Voss and Jansa [8]. Voss and Jansa [8] treated Micoureus as a subgenus of Marmosa in order to keep Marmosa as a monophyletic genus. In contrast, we keep Micoureus as a full genus, which leaves Marmosa paraphyletic, but future studies will probably resolve this situation by recognizing additional genera. The monophyly of Micoureus is well supported [8] and warrants recognition at the taxonomic level of genus and not subgenus.

The COI gene was sequenced from 73 specimens belonging to 11 species and 10 genera of didelphid marsupials. Additional COI sequences used in the present paper are from Borisenko et al., [21] and are available online at the Barcode of Life Data System (BOLD; www.barcodinglife.org), in the projects 'Small mammal survey in Bakhuis, Suriname (ABSMS)' and 'Small mammal survey in Bakhuis reference sequences (ABSMC)'. Total taxonomic diversity for COI was 26 species in 10 genera. CytB sequences were obtained from 70 specimens belonging to 12 species of 10 didelphid genera. There were 55 of 89 specimens that had both COI and CytB sequenced. The results presented in this paper are part of the project 'Barcoding Atlantic Forest Opossums (BATFO)', which is also available in BOLD. All sequences are deposited in GenBank (www.ncbi.nlm.nih.gov) and are associated to voucher specimens (Appendix), which were identified to the species level using morphological characters. Detailed museum and locality data of voucher specimens are also available in BOLD.

DNA was extracted using a salt protocol [24], and the product was quantified in a NanoDrop 1000 spectrophotometer (Thermo Fisher Scientific Inc.). Samples with high concentration were diluted to $100 \mathrm{ng} / \mu \mathrm{L}$ with $\mathrm{ddH}_{2} \mathrm{O}$. Both COI (657 bp) and CytB (801 bp) sequences were amplified through the polymerase chain reaction (PCR). The $25 \mu \mathrm{L}$ PCR reaction solution included $2.5 \mu \mathrm{L}$ of $10 \times$ PCR buffer, $1.0 \mu \mathrm{L}$ of $\mathrm{MgCl}_{2}(50 \mathrm{mM}), 0.5 \mu \mathrm{L}$ of dNTP mixture $(10 \mathrm{mM}$ each oligonucleotide), $0.3 \mu \mathrm{L}$ of Platinum Taq DNA polymerase (Invitrogen), $0.3 \mu \mathrm{L}$ of each primer $(10 \mu \mathrm{M})$, and $2 \mu \mathrm{L}$ of DNA template $(100 \mathrm{ng} / \mu \mathrm{L})$. For the COI amplification, we used the forward primer LCO1490 (5'GGTCAACAAATCATAAAGATATTGG-3'), and the reverse primer HCO2198 (5'-TAAACTTCAGGGTGACCAAAAAATCA-3') [25] under the following PCR profile: $94{ }^{\circ} \mathrm{C}$ for $5 \mathrm{~min}$, followed by 39 cycles of $94{ }^{\circ} \mathrm{C}$ for $30 \mathrm{~s}, 44$ ${ }^{\circ} \mathrm{C}$ for $45 \mathrm{~s}, 72{ }^{\circ} \mathrm{C}$ for $45 \mathrm{~s}$, and a final cycle of $72{ }^{\circ} \mathrm{C}$ for 5 min. For the CytB amplification, we used the forward primer MVZ05 (5'-CGAAGCTTGATATGAAAAACCATCGTTG$3^{\prime}$ ) and the reverse primer MVZ16 (5'- AAATAGGAARTATCAYTCTGGTTTRAT-3') [26] under the following PCR regime: $94{ }^{\circ} \mathrm{C}$ for $5 \mathrm{~min}$, followed by 39 cycles of 94 ${ }^{\circ} \mathrm{C}$ for $30 \mathrm{~s}, 48{ }^{\circ} \mathrm{C}$ for $45 \mathrm{~s}, 72{ }^{\circ} \mathrm{C}$ for $45 \mathrm{~s}$, and a final cycle of $72{ }^{\circ} \mathrm{C}$ for $5 \mathrm{~min}$. PCR products were purified using enzymes ExoSap-IT (USB Corporation) and cycle sequenced using BigDye Terminator 3.1 (Applied Biosystems, Inc.) during 25 cycles of $95^{\circ} \mathrm{C}$ for $30 \mathrm{~s}, 50{ }^{\circ} \mathrm{C}$ for $15 \mathrm{~s}, 60^{\circ} \mathrm{C}$ for $4 \mathrm{~min}$. After precipitation in isopropanol/ethanol, the product was sequenced in both directions using an automated capillary sequencer ABI 310 (Applied Biosystems, Inc.).

$\mathrm{COI}$ and $\mathrm{CytB}$ sequences were aligned using ClustalW in MEGA 4.0 [27]. Neighbor-joining (NJ) trees based on the Kimura two-parameter distance model (K2P) were generated in MEGA 4.0 and support for each node was estimated using 100 bootstrap replicates. Sequences were submitted to species identification using the Identification Engine in BOLD (BOLD-IDS). This engine accepts sequences from the $5^{\prime}$ region of the mitochondrial gene $\mathrm{COI}$, and returns a specieslevel identification when one is possible. Inter and intraspecific divergences were calculated using K2P in BOLD.

\section{RESULTS}

In the overall COI NJ tree (Fig. 1), specimens of the same species always grouped together with high bootstrap support (99\%), except for $M$. demerarae. Two specimens from Ecuador (ROM104494 and ROM105521) identified in BOLD as $M$. demerarae grouped together, but not with the remaining $M$. demerarae. Species of the same genus also grouped together, except for Marmosops, but with lower bootstrap support $(<81 \%$; Fig. 1). There is generally no support for intergeneric groupings, with the exception of the large opossums Didelphis, Philander, and Chironectes at 79$91 \%$ (Fig. 1). Individuals of the same species also always grouped together in the CytB NJ tree (Fig. 2), with high bootstrap support $(>98 \%)$. Species of Monodelphis also clustered together with high bootstrap support $(81 \%)$, and Philander frenatus and Didelphis aurita formed a wellsupported group (93\%).

The average intraspecific COI divergence was $2.0 \%$, which was more than five times less than interspecific variation within each genus (11.2\%), and almost ten times less than the divergence among genera of the same family $(19.5 \%)$ (Table 1). Micoureus demerarae showed the highest average intraspecific divergence (5.0\%) followed by Gracilinanus microtarsus (4.2\%), whereas Didelphis aurita showed negligible intraspecific variation $(0.1 \%)$. Some species showed extreme values of intraspecific COI divergences, ranging from 0 to $9.2 \%$ in Metachirus nudicaudatus, 0 to $8.4 \%$ in M. demerarae, and 0.5 to $7.2 \%$ in G. microtarsus. 


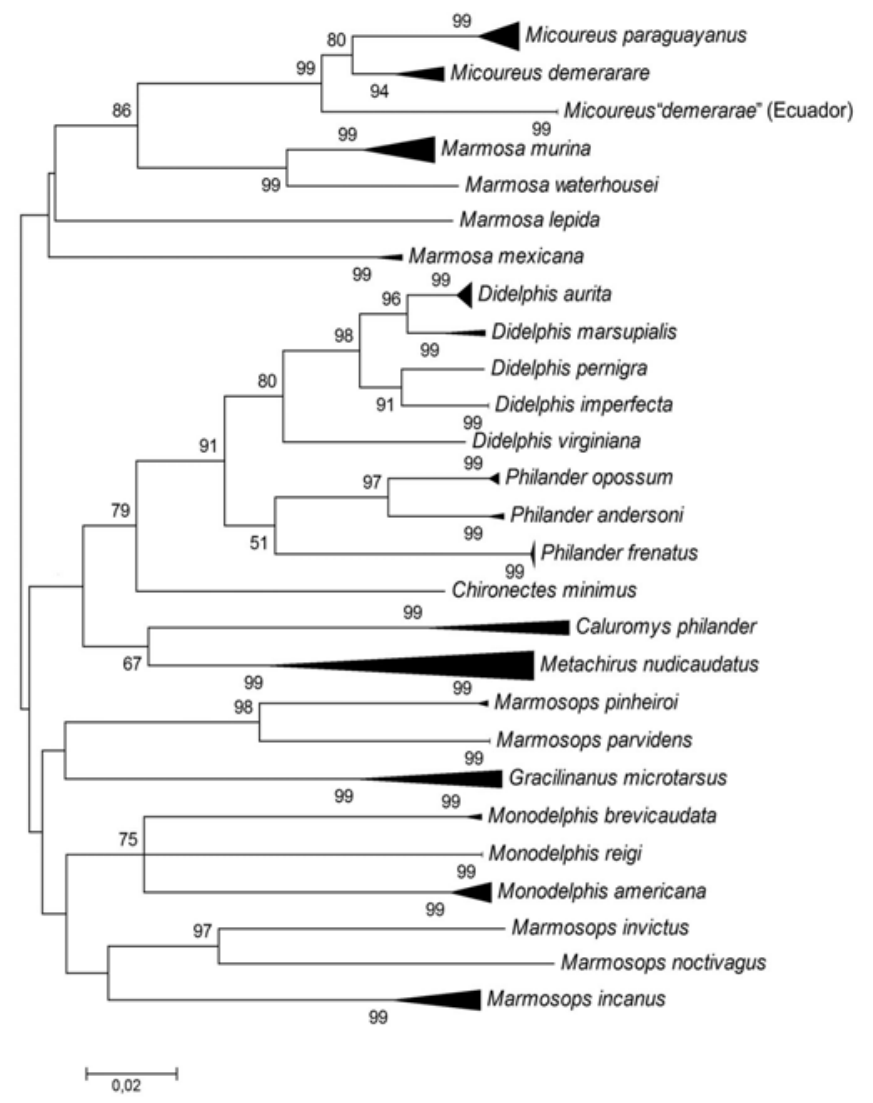

Fig. (1). Neighbor-joining tree constructed using sequences of the cytochrome oxidase subunit I (COI) gene of didelphid species. Numbers represent bootstrap support values (\%).

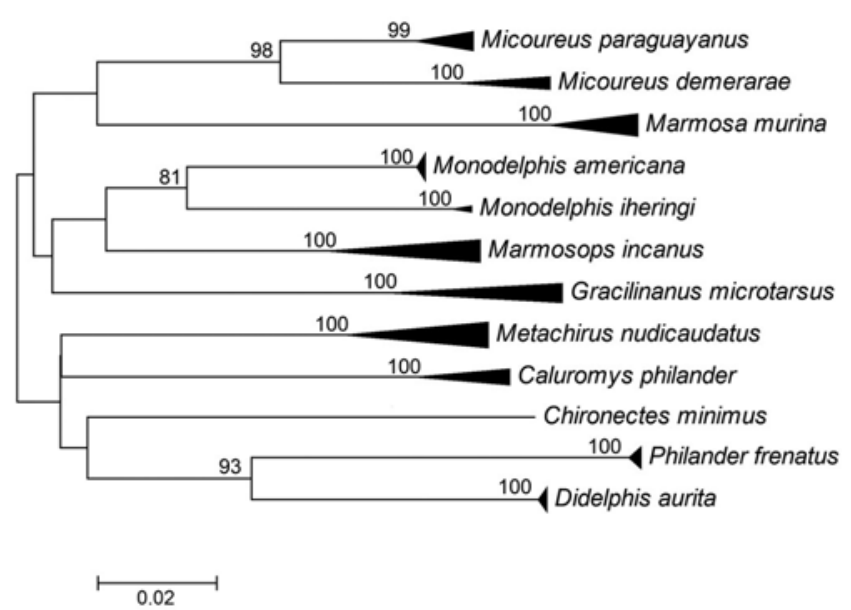

Fig. (2). Neighbor-joining tree constructed using sequences of the cytochrome b (CytB) gene of didelphid species. Numbers represent bootstrap support values (\%).

The average intraspecific $\mathrm{CytB}$ divergence $(1.9 \%)$ was virtually the same as the COI gene (Table 1). The average CytB divergence among species of the same genus (10.8\%) was more than five times higher than the intraspecific divergence, and the average distance among genera of the same family $(21.3 \%)$ was more than ten times higher than the intraspecific distance. The lowest average $\mathrm{CytB}$ divergence was found within Monodelphis americana $(0.2 \%)$ and the highest in Marmosops incanus $(5.0 \%)$. The highest value within species was observed in $M$. incanus $(9.1 \%)$.

The taxonomic identification of all COI sequences matched with identifications on BOLD-IDS database. How-

Table 1. Genetic Distances of the Cytochrome c Oxidase Subunit I (COI) and the Cytochrome b (CytB) Genes of Ten Species and within Three Taxonomic Ranks of Didelphid Marsupials. $n=$ number of Sequences

\begin{tabular}{|c|c|c|c|c|c|c|c|c|}
\hline \multirow{2}{*}{ Species/Rank } & \multicolumn{4}{|c|}{ COI Genetic Distance (\%) } & \multicolumn{4}{|c|}{ CytB Genetic Distance (\%) } \\
\hline & $\mathbf{n}$ & Minimum & Maximum & Mean & $\mathbf{n}$ & Minimum & Maximum & Mean \\
\hline Caluromys philander & 5 & 0.3 & 4.7 & 3.1 & 5 & 0.5 & 6.2 & 3.8 \\
\hline Didelphis aurita & 9 & 0.0 & 0.3 & 0.1 & 8 & 0.0 & 0.8 & 0.4 \\
\hline Gracilinanus microtarsus & 6 & 0.5 & 7.2 & 4.2 & 6 & 0.0 & 8.7 & 3.7 \\
\hline Marmosa murina & 9 & 0.0 & 4.0 & 2.4 & 7 & 0.0 & 5.6 & 2.9 \\
\hline Marmosops incanus & 7 & 0.2 & 4.6 & 3.1 & 7 & 0.5 & 9.1 & 5.0 \\
\hline Metachirus nudicaudatus & 10 & 0.0 & 9.2 & 3.9 & 8 & 0.4 & 6.1 & 2.5 \\
\hline Micoureus demerarae & 7 & 0.0 & 8.4 & 5.0 & 4 & 0.8 & 4.3 & 3.1 \\
\hline Micoureus paraguayanus & 10 & 0.2 & 2.3 & 1.3 & 6 & 0.4 & 2.6 & 1.6 \\
\hline Monodelphis americana & 7 & 0.0 & 2.0 & 0.7 & 9 & 0.0 & 0.4 & 0.2 \\
\hline Philander frenatus & 9 & 0.0 & 0.6 & 0.3 & 7 & 0.0 & 1.3 & 0.4 \\
\hline Within species & 99 & 0.0 & 9.2 & 2.0 & 69 & 0.0 & 9.1 & 1.9 \\
\hline Among species & 106 & 2.5 & 20.9 & 11.2 & 69 & 8.3 & 13.5 & 10.8 \\
\hline Among genera & 107 & 10.3 & 24.9 & 19.5 & 70 & 12.9 & 25.9 & 21.3 \\
\hline
\end{tabular}


ever, two specimens of $M$. demererae from Ecuador (ROM 104494 and ROM 105521) probably represent a different species not currently on BOLD (see Lim, this issue).

\section{DISCUSSION}

In the current paper, we added 3 genera (Caluromys, Chironectes, and Gracilinanus) and 8 species (Caluromys philander, Chironectes minimus, Gracilinanus microtarsus, Marmosops incanus, Micoureus paraguayanus, Monodelphis americana, Philander frenatus, and Didelphis aurita) to the published COI database in BOLD, increasing the taxonomic coverage of didelphid marsupials to 10 genera and 26 species, which represents over half of the genera and one third of the current species recognized in this group. In addition, we expanded sample sizes within species and especially the geographic coverage to include the Atlantic Forest of eastern South America, an area of unique biodiversity with many endemic species [22].

Previous molecular studies suggested genetic distances among congeneric species are usually above $2-3 \%$ for both COI and CytB [28, 29]. In didelphids, the average CytB divergence among congeneric species reaches more than $15 \%$ in some genera, such as Marmosa and Micoureus [30], which is similar to the interspecific divergences found here. But the overall average within species was relatively high (1.9-2.0\%) for both genes. These intraspecific divergences are, however, slightly overestimated because of our sampling strategy. Since our sample size was small (usually 5-10 specimens/species), our priority was to sample sequence variation across the geographic range of each species, so we chose specimens from distant localities whenever possible. This probably inflated the intraspecific distances when compared to a large sample of specimens randomly taken from the species distribution.

Our COI results suggest that the two $M$. "demerarae" from Ecuador (ROM104494 and ROM105521) are likely to represent another species because they did not group with the other $M$. demerarae in the NJ tree and they show relatively high genetic distances from them (7.6-8.3\%). In addition, current data indicates that $M$. demerarae does not occur in Ecuador [2]. This is the kind of situation where molecular data are very helpful in diagnosing species, but the true identity of the two ROM specimens can only be confirmed by the examination of the voucher specimens in a comprehensive taxonomic revision of the genus.

Some didelphid species have an old evolutionary history, and we expect more genetic variation and eventually more phylogeographic structure in older diverged than more recently diverged species [31]. For example, one specimen of M. nudicaudatus from Surinam (ROM117525) and another one from Guyana (ROM111938), showed very high divergence values $(8.6-9.0 \%)$ when compared to the remaining specimens $(<2.8 \%)$. The high genetic divergences of $M$. nudicaudatus from the Guyana shield, when compared to specimens from the Brazilian shield, has been pointed out by other authors [3, 30, 32]. These high levels of genetic divergence associated with deep phylogeographic discontinuities across its range, coupled with morphological and morphometric analyses of museum specimens (Carlos L. G. Vieira, unpublished data) suggest that Metachirus nudicaudatus is a composite and should be split into several species.

Although high values of intraspecific genetic divergences suggest that more than one species might be involved, additional data do not always confirm this trend. For example, when analyzing COI sequences of G. microtarsus, two specimens from southeastern Brazil (LPC822 and YL01) inflated the divergence values $(4.8-7.1 \%)$, in relation to comparisons without these specimens $(0.4-2.3 \%)$. Using CytB sequences, Costa et al., [33] proposed the possibility of two species within $G$. microtarsus, but a recent reassessment of morphological and genetic variation across the range of $G$. microtarsus (Simone L. Freitas, unpublished data) found incongruence among mitochondrial DNA sequences and morphological character variation, concluding that this taxon should be treated as a single species with deep phylogeographic structure.

The present study has shown that both COI and CytB are useful in providing characters for molecular diagnosis of didelphid species, confirming that divergence levels among closely related species are usually higher than within species in both mitochondrial genes. The barcoding gap is almost the same for COI and CytB, indicating that either gene can be used in molecular diagnosis of didelphids. Recent research [34] suggests that mitochondrial bioenergetics plays a key role in multiple basic cellular processes and could be a candidate genetic mechanism of speciation. Under this scenario, mitochondrial sequences could be responsible for undermining the reproductive compatibility within a species when they conflict with sequences in the nucleus, which differ by an order of magnitude in their mutation rates [34]. This is a new perspective, which associates the DNA barcoding pattern with the process of speciation, but it still remains to be confirmed [35]. Nonetheless, DNA barcodes are a welcome addition to traditional taxonomic methods when viewed as additional diagnostic characters in the context of an integrative taxonomy $[9,13]$.

\section{ACKNOWLEDGMENTS}

We owe special thanks to M.P.L. Silva, A.S. Neves, and J.L. Patton for sharing important CytB sequences. S. Lóss, V. Fagundes, and Helio Q.B. Fernandes (MBML) provided additional tissue samples used in the present study. Fundação de Apoio à Ciência e Tecnologia do Espírito Santo (FAPES) supported this project through a research grant to YLRL. The Critical Ecosystem Partnership Fund (CEPF) funded most of the equipment and some reagents. APCF had scholarship support from Fundo de Apoio à Ciência e Tecnologia do Município de Vitória (FACITEC), ACL had scholarship support from Coordenação de Aperfeiçoamento de Pessoal de Nível Superior (CAPES), JA and RD had scholarship support from UFES and FAPES, and YLRL has a fellowship from Conselho Nacional de Desenvolvimento Científico e Tecnológico $(\mathrm{CNPq})$. Many colleagues from the Mammalogy and Biogeography Lab at UFES provided valuable help, especially J.F. Justino, manager of the molecular lab. 
APPENDIX. GenBank Accession Numbers for Cytochrome c Oxidase Subunit I (COI) and Cytochrome b (CytB) Sequences Generated in this Study with Association to Species, Sample Number and Barcode Number Catalogued in the Barcode of Life Data System (BOLD).

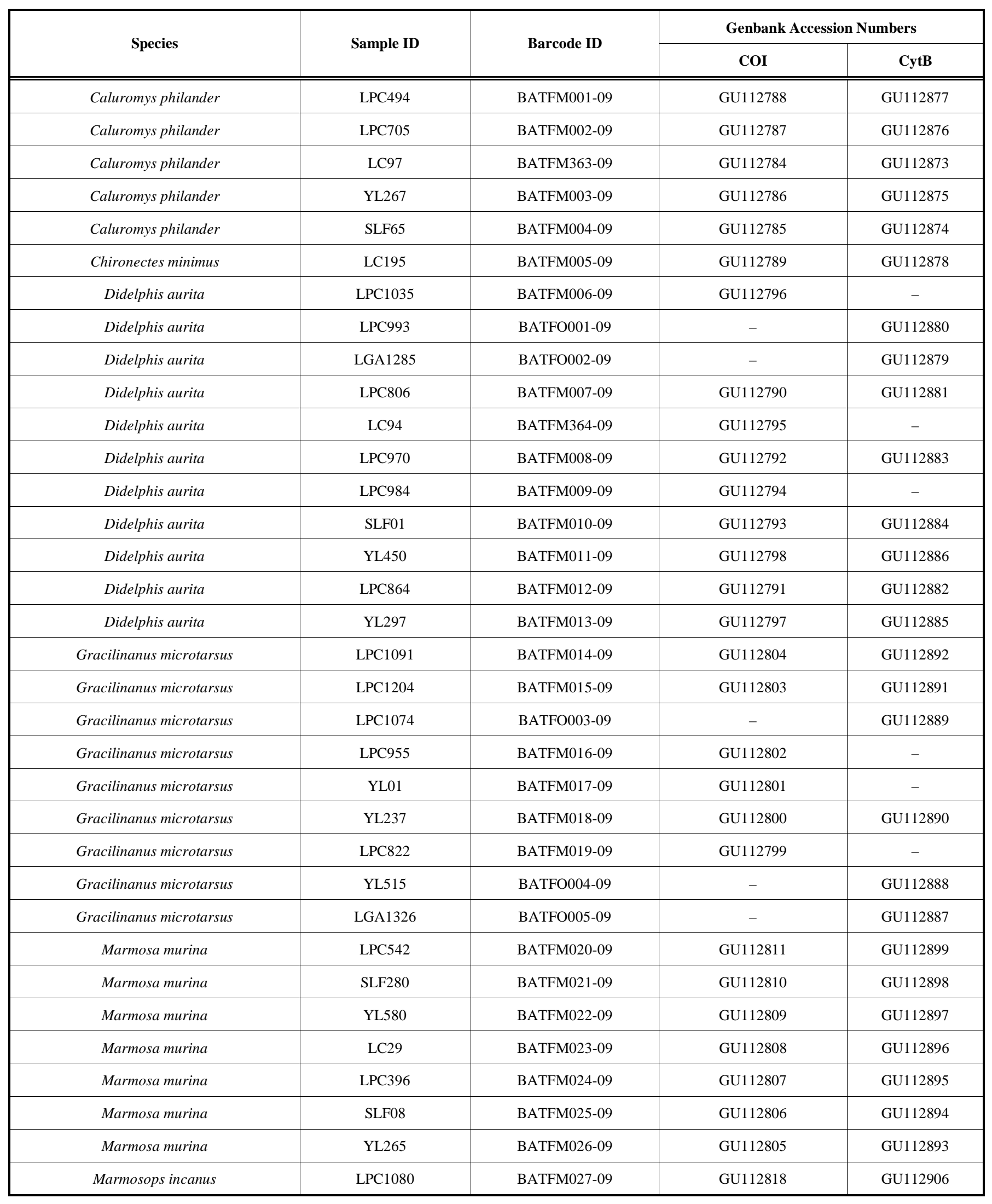


(APPENDIX) Contd....

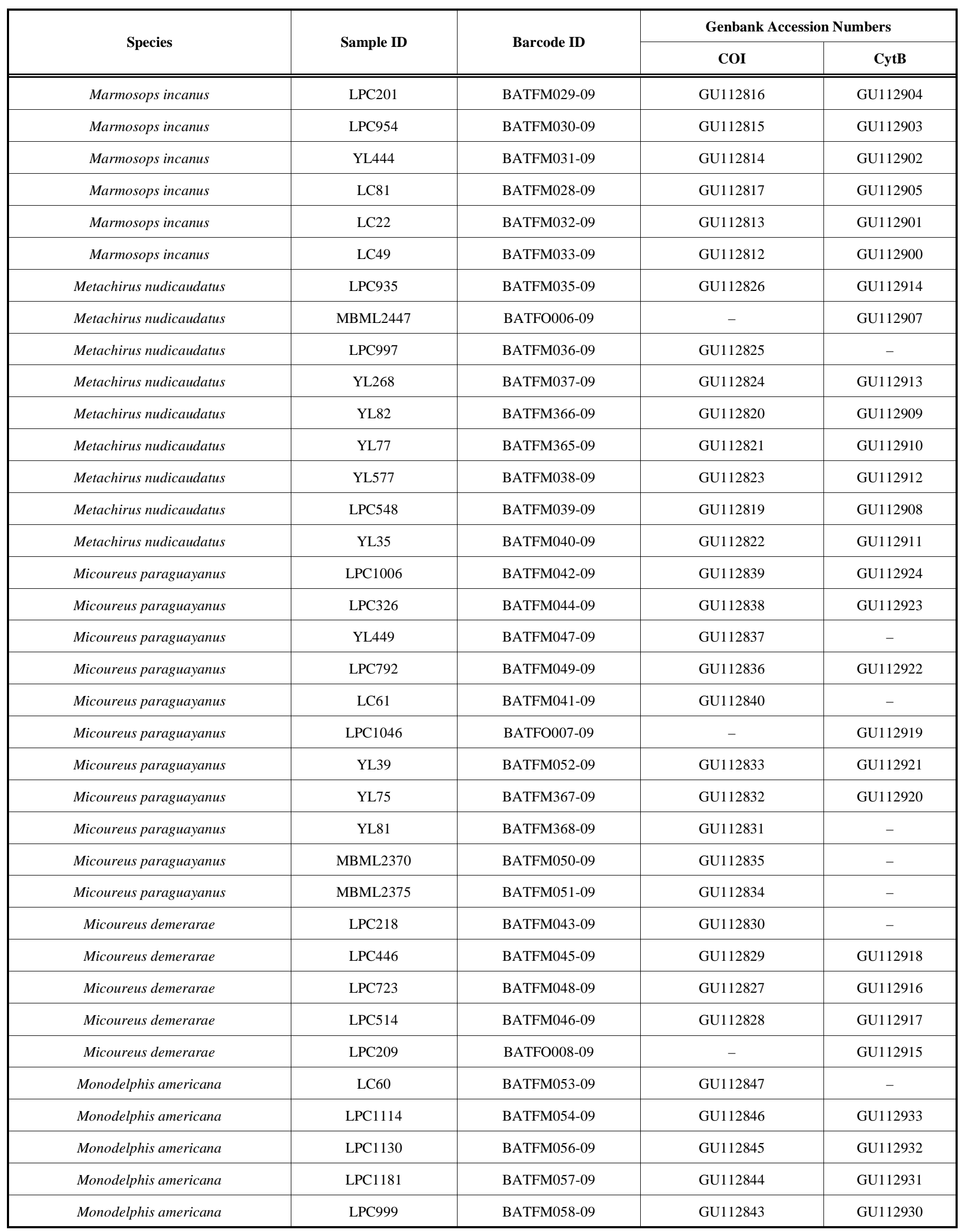


(APPENDIX) Contd....

\begin{tabular}{|c|c|c|c|c|}
\hline Species & Sample ID & Barcode ID & \multicolumn{2}{|c|}{ Genbank Accession Numbers } \\
\hline Monodelphis americana & MBML2710 & BATFM063-09 & GU112841 & - \\
\hline Monodelphis americana & LPC991 & BATFO009-09 & - & GU112928 \\
\hline Monodelphis americana & LPC990 & BATFO011-09 & - & GU112926 \\
\hline Monodelphis americana & LPC1028 & BATFO012-09 & - & GU112925 \\
\hline Monodelphis iheringi & LPC1124 & BATFM055-09 & - & GU112935 \\
\hline Monodelphis iheringi & MBML2346 & BATFM061-09 & - & GU112934 \\
\hline Philander frenatus & ORG01 & BATFO013-09 & - & GU112937 \\
\hline Philander frenatus & YL232 & BATFM066-09 & GU112854 & - \\
\hline Philander frenatus & YL52 & BATFM067-09 & GU112850 & - \\
\hline Philander frenatus & YL107 & BATFM369-09 & GU112848 & GU112938 \\
\hline Philander frenatus & YL573 & BATFM068-09 & GU112853 & GU112940 \\
\hline Philander frenatus & YL579 & BATFM069-09 & GU112852 & - \\
\hline Philander frenatus & LPC877 & BATFM070-09 & GU112851 & GU112939 \\
\hline
\end{tabular}

\section{CONFLICT OF INTEREST}

None declared.

\section{REFERENCES}

[1] Voss RS, Lunde DP, Simmons NB. The mammals of Paracou, French Guiana: a neotropical lowland rainforest fauna. Part 2. Nonvolant species. Bull Am Mus Nat Hist 2001; 263: 1-236.

[2] Gardner AL, Ed. Mammals of South America. Vol. 1. Marsupials, xenarthrans, shrews, and bats. Chicago: Chicago University Press 2008.

[3] Patton JL, Costa LP. In: Jones ME, Dickman CR, Archer M, Eds. Predators with pouches: the biology of carnivorous marsupials. Collingwood: CSIRO Publishing. 2003; pp. 63-81.

[4] Gardner AL. In: Wilson DE, Reeder DM, Eds. Mammal species of the world. $2^{\text {nd }}$ ed. Washington: Smithsonian Institution Press 1993; pp. 15-23.

[5] Gardner AL. In: Wilson DE, Reeder DM, Eds. Mammal species of the world. $3^{\text {rd }}$ ed. Baltimore: Johns Hopkins University Press 2005; pp. 3-18.

[6] Voss RS, Gardner AL, Jansa SA. On the relationships of "Marmosa" formosa Shamel, 1930 (Marsupialia: Didelphidae), a phylogenetic puzzle from the Chaco of northern Argentina. Am Mus Novitates 2004; 3442: 1-18.

[7] Voss RS, Lunde DP, Jansa SA. On the contents of Gracilinanus Gardner and Creighton, 1989, with the description of a previously unrecognized clade of small didelphid marsupials. Bull Am Mus Nat Hist 2005; 3482: 1-34.

[8] Voss RS, Jansa SA. Phylogenetic relationships and classification of didelphid marsupials, an extant radiation of New World metatherian mammals. Bull Am Mus Nat Hist 2009; 322: 1-177. and the need for integrative taxonomy. Syst Biol 2005; 54: 844-51. Bickford D, Lohman DJ, Sodhi NS, et al. Cryptic species as a window on diversity and conservation. Trends Ecol Evol 2006; 22: 148-55.

[11] Hebert PDN, Penton EH, Burns JM, Janzen DH, Hallwachs W. Ten species in one: DNA barcoding reveals cryptic species in the neotropical skipper butterfly Astraptes fulgerator. Proc Natl Acad Sci USA 2004; 101: 14812-7.

[12] Hebert PDN, Cywinska A, Ball SL, deWaard JR. Biological identifications through DNA barcodes. Proc R Soc Lond B 2003; 270: 313-21.

[13] Dayrat B. Towards integrative taxonomy. Biol J Linn Soc 2005; 85: 407-15.

[14] Avise JC, Arnold J, Ball RM, et al. Intraspecific phylogeography: the mitochondrial DNA bridge between population genetics and systematics. Ann Rev Ecol Syst 1987; 18: 489-522.

[15] Meyer CP, Paulay G. DNA barcoding: error rates based on comprehensive sampling. Plos Biol 2005; 3: e422.

[16] Hebert PDN, Ratnasingham S, deWaard JR. Barcoding animal life: cytochrome c oxidase subunit 1 divergences among closely related species. Proc R Soc Lond B 2003; 270(Suppl.): S96-9.

[17] Waugh J. DNA barcoding in animal species: progress, potential and pitfalls. Bioessays 2007; 29: 188-97.

[18] Moritz C, Cicero C. DNA Barcoding: promise and pitfalls. Plos Biol 2004; 2: 1529-31.

[19] Wiemers M, Fiedler K. Does the DNA barcoding gap exist? - a case study in blue butterflies (Lepidoptera: Lycaenidae). Front Zool 2007; 4: 8 . 
[20] Clare EL, Lim BK, Engstrom MD, Eger JL, Hebert PDN. DNA barcoding of Neotropical bats: species identification and discovery within Guyana. Mol Ecol Notes 2007; 7: 184-90.

[21] Borisenko AV, Lim BK, Ivanova NV, Hanner RH, Hebert PDN. DNA barcoding in surveys of small mammal communities: a field study in Suriname. Mol Ecol Res 2008; 8: 471-9.

[22] Mittermeier RA, Gil PR, Hoffman, M, et al. Hotspots revisited: Earth's biologically richest and most endangered terrestrial ecoregions. Washington: Conservation International 2005.

[23] Bradley RD, Baker RJ. A test of the genetic species concept: cytochrome-b sequences and mammals. J Mammal 2001; 82: 96073.

[24] Bruford MW, Hanotte O, Brookfield JFY, Burke T. In: Hoelzel AR, Ed. Molecular genetic analyses of populations: a practical approach. New York: Oxford University Press. 1992; pp. 225-69.

[25] Folmer O, Black M, Hoeh W, Lutz R, Vrijenhoek R. DNA primers for amplification of mitochondrial cytochrome $\mathrm{c}$ oxidase subunit I from diverse metazoan invertebrates. Mol Mar Biol Biotech 1994; 3: 294-9.

[26] Smith MF, Patton JL. The diversification of South American murid rodents: evidence from mitochondrial DNA sequence data for the akodontine tribe. Biol J Linn Soc 1993; 50: 149-77.
[27] Tamura K, Dudley J, Nei M, Kumar S. MEGA4: Molecular Evolutionary Genetics Analysis (MEGA) software version 4.0. Mol Biol Evol 2007; 24: 1596-9.

[28] Hebert PDN, Stoeckle MY, Zemlak TS, Francis CM. Identification of birds through DNA barcodes. PLoS Biol 2004; 2: 1657-63.

[29] Johns GC, Avise JC. A comparative summary of genetic distances in the vertebrates from the mitochondrial cytochrome $b$ gene. Mol Biol Evol 1998; 15: 1481-90.

[30] Patton JL, Da Silva MNF, Malcolm JR. Mammals of the Rio Jurua and the evolutionary and ecological diversification of Amazonia. B Am Mus Nat Hist 2000; 244: 1-306.

[31] Avise JC. Phylogeography: The history and formation of species. Cambridge: Harvard University Press 2000.

[32] Costa LP. The historical bridge between the Amazon and the Atlantic Forest of Brazil: a study of molecular phylogeography with small mammals. J Biogeogr 2003; 30: 71-86.

[33] Costa LP, Leite YLR, Patton JL. Phylogeography and systematic notes on two species of gracile mouse opossums, genus Gracilinanus (Marsupialia, Didelphidae). P Biol Soc Wash 2003; 116: 275-92.

[34] Gershoni M, Templeton AR, Mishmar D. Mitochondrial bioenergetics as a major motive force of speciation. BioEssays 2009; 31: 642-50.

[35] Lane N. On the origin of bar codes. Nature 2009; 462: 272-4.

(C) Agrizzi et al; Licensee Bentham Open.

This is an open access article licensed under the terms of the Creative Commons Attribution Non-Commercial License (http://creativecommons.org/licenses/by-nc/3.0/) which permits unrestricted, non-commercial use, distribution and reproduction in any medium, provided the work is properly cited. 